\title{
Using a plant health system framework to assess plant clinic performance in Uganda
}

\author{
Solveig Danielsen ${ }^{1,2} \cdot$ Frank B. Matsiko $^{3}$ \\ Received: 11 September 2014 / Accepted: 7 December 2015 / Published online: 20 January 2016 \\ (C) The Author(s) 2016. This article is published with open access at Springerlink.com
}

\begin{abstract}
Systems thinking is commonly applied to understand the complexities of human healthcare delivery. In contrast, plant health systems as an organising principle have evolved more recently from work with plant clinics as providers of plant healthcare services to farmers. As plant health systems evolve and expand, new analytical frameworks and tools are needed to identify factors influencing performance of services and systems in specific contexts, and to guide interventions. In this paper we apply a plant health system framework to assess plant clinic performance, using Uganda as a case study. A comparative study of plant clinics was carried out between July 2010 and September 2011 in the 12 districts where plant clinics were operating at that time. The framework enabled us to organise multiple issues and identify key features that affected the plant clinics. Clinic performance was, among other factors, influenced by basic operational and financial concerns, inter-institutional relations and public sector policies. Overall, there was a fairly close match between the plant health system attributes and plant clinic performance, suggesting that the framework can help explain system functioning and identify intervention points and domains for strengthening plant health systems. The plant health
\end{abstract}

Solveig Danielsen

s.danielsen@cabi.org

Frank B. Matsiko

fbmatsiko@gmail.com; fbmatsiko@caes.mak.ac.ug

1 Centre for Health Research and Development, University of Copenhagen, Copenhagen, Denmark

2 Present address: CABI, Kastanjelaan 5, 3833 AN Leusden, The Netherlands

3 Department of Agricultural Extension \& Innovations, Makerere University, Kampala, Uganda system framework needs further testing to explore the full scope of the method, including assessing the relative importance and interactions of the system components, and tracking attributions and outcomes over time.

Keywords Uganda · Plant health system framework · Plant clinics · Performance assessment $\cdot$ Plant health $\cdot$ Agricultural extension

\section{Introduction}

Following decades of large investments into the control of single diseases (HIV/AIDS, tuberculosis, malaria) in developing countries, there is increasing recognition that more attention needs to be paid to general health system strengthening to enhance responsiveness to the multiple causes of ill-health (Bowser et al. 2013; Vega 2013). Strengthening health systems is therefore now high on the international human health agenda (WHO 2007; Balabanova et al. 2010). Literature on performance assessment of human health systems has expanded rapidly in recent years (Backman et al. 2008; Wendt et al. 2009; Mitchell and Bossert 2010). In contrast, plant health system research is a relatively novel field of study which has emerged from the plant clinic pioneer initiatives of the past decade.

Effective plant health management is a key contributor to food security and safety and to meeting the demands of local and global markets. For small-scale farmers in most developing countries, however, plant health advisory services are either limited in scope and content, or altogether nonexistent (Smith et al. 2008; Miller et al. 2009). Conventional pest management interventions tend to focus on a narrow range of crops, diseases and technologies, despite the fact that smallholder farmers depend on dozens of crops for food, 
medicines, fodder and income. Enhanced responsiveness to plant health threats takes on added urgency and importance in a global context of emerging exotic diseases and unpredictable disease patterns induced by climate change and the increased mobility of people and goods.

To overcome some of the limitations commonly associated with conventional plant health management interventions, plant clinics have been established since 2003 in a number of countries across Africa, Asia and Latin America (Boa 2009; Romney et al. 2013). These clinics are an innovative way to improve plant healthcare for smallholder farmers. A plant clinic is operated as a community-based service, open to everyone and run by 'plant doctors' (local extension workers) in public locations such as local markets, bus stations or farmer cooperatives (Boa 2009). Normally the plant doctors combine plant clinic work with their regular extension roles. The plant doctors are essentially modelled after the 'community health workers', who have been successful in human and animal health in many developing countries (Catley et al. 2004; WHO 2008).

The plant clinic approach represents a shift from a 'vertical' (single crop or single pest) to a 'horizontal' approach (any problem in any crop). Just as primary care in human health has proven to be an effective platform for health system strengthening in several countries (Kruk et al. 2010; Pallas et al. 2012), plant clinics have turned out to be a valuable entry point for strengthening plant health. Results from pioneer plant clinics in Nicaragua 2005-2007 demonstrated the clinics' potential to create synergies between different actors in plant health, thus making better use of existing resources (Danielsen et al. 2013a). The Nicaraguan experience fostered a broad 'plant health system' idea, which recognises that attainment of plant health outcomes requires functional linkages among key actors: farmers; extension services; regulatory bodies; education and research institutions; agricultural input; and information suppliers. These functions exist in every country, but rarely operate as a coherent system. Since 2012, 'plant health system strengthening' has gained global attention through CABI's rapidly expanding programme, Plantwise. $^{1}$

The shift from project-based, single-disease interventions to 'plant health system strengthening' poses new challenges for implementers, decision-makers and researchers. As plant health systems expand and evolve, new analytical frameworks and tools are needed to identify factors influencing performance in different institutional, political and socio-cultural contexts, and to guide interventions. Although Prof. J. Artie Browning already in 1983 advocated for a holistic systems approach to plant health that embraces plant health care,

\footnotetext{
${ }^{1}$ Plantwise is a global, CABI managed programme, aiming at strengthening plant health systems through plant clinics in Africa, Asia and Latin America (34 countries in 2015): www.plantwise.org
}

research, teaching and delivery systems (Browning 1983), current plant health system frameworks tend to focus narrowly on quarantine systems, phytosanitary certification, pest surveillance, pest risk analysis, research and capacity building. ${ }^{2,3,4,5}$ Existing literature on plant clinics on the other hand, focuses on specific aspects of clinic operations, use, scope and quality (Bentley et al. 2009; Danielsen and Kelly 2010; Negussie et al. 2011; Danielsen et al. 2013b). How plant clinics fit within and are influenced by the wider plant health system remains largely unexplored.

In this paper we use a plant health system framework derived from human health system research to assess plant clinic performance, using Uganda as a case study. The paper adapts the WHO's (2007) definition of a health system: 'a plant health system consists of all organizations, people and actions whose primary intent is to promote, restore or maintain plant health'. We describe the evolution of plant clinics in Uganda from 2006 to 2011, assess their performance, and identify plant health system related factors that influence this performance. Finally, we discuss the implications of the findings for plant health system strengthening in Uganda and the applicability of the plant health system framework for further research. The research is part of ongoing efforts to develop methods and approaches to study plant clinics and plant health systems and to identify determinants of plant health.

\section{Uganda: from plant clinics to a plant health system approach}

Beginning in 2006, plant clinics were piloted in three districts of Uganda as a new way to provide plant health advice to farmers. The initiative was a collaborative effort among Local Governments (LGs), non-governmental organisations (NGOs) and Ministry of Agriculture, Animal Industries and Fisheries (MAAIF), guided and supported by the Global Plant Clinic (GPC) of $\mathrm{CABI}^{6}$ (Danielsen and Mutebi 2010). After an inactive period in 2009, plant clinics were incorporated into MAAIF's 5-year Development Strategy and Investment Plan (DSIP) in 2010 (MAAIF 2010). Department of Crop Protection of MAAIF recognised that plant clinics have the potential to provide a valuable farmer service to help deal with the rampant pests and diseases (interviews with senior officials from MAAIF). The strategic potential of the plant clinics to

\footnotetext{
${ }^{2}$ http://app.ava.gov.sg/data/Publications/ListOfPublications/ava_vision_ issues3-4_2013/plant-picks-european-commission-audit.html Accessed 16 March 2015

${ }^{3}$ www.agriculture.gov.au/plant/health/plant-health-in-australia Accessed 16 March 2015

${ }^{4} \mathrm{http}$ ://feedthefuture.gov/article/helping-develop-capacity-plantprotection-and-quarantine Accessed 16 March 2015

${ }_{5}^{5}$ www.agriconsultingeurope.be/plant-health Accessed 16 March

${ }^{6}$ The Global Plant Clinic evolved into Plantwise in 2012.
} 
Fig. 1 Evolution of the plant clinic initiative in Uganda 20062011

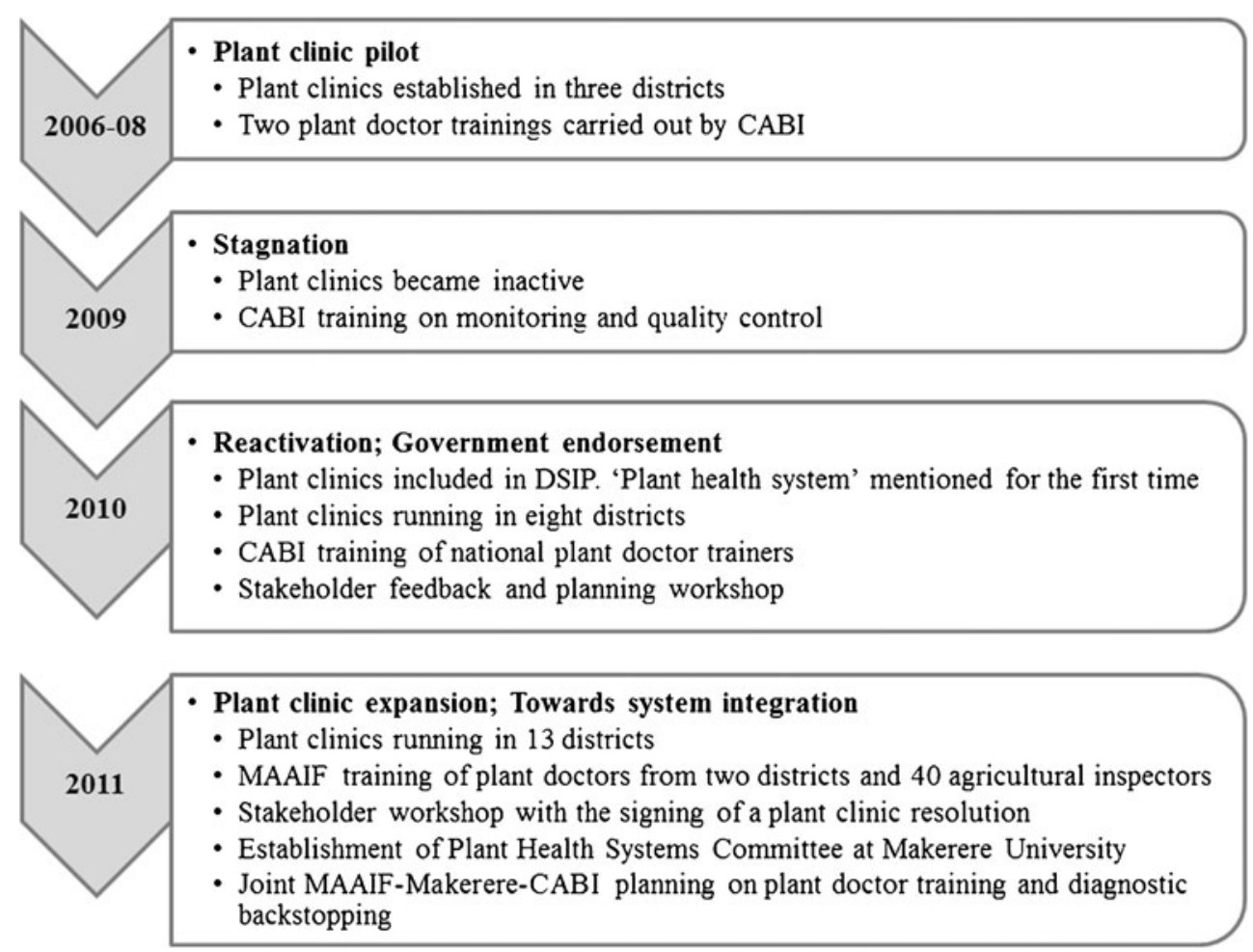

foster system strengthening is highlighted in the DSIP: 'The plant clinics have a broad potential to help glue together the various systems. They are first and foremost a communitybased plant health service for farmers, but if properly connected to other institutions and services, the synergies with surveillance, quarantine, research, other advisory services and input suppliers can be quite substantial.' Figure 1 summaries key milestones in the development of plant clinics in Uganda and the early moves towards a plant health system approach from 2006 to 2011.

According to the DSIP, LGs and NGOs are responsible for implementing the plant clinics with guidance, supervision and backstopping from MAAIF. Following government endorsement, and fuelled by small start-up grants from CABI, plant clinics expanded into 12 districts in 2010 and 2011. The Department of Crop Protection created a small core team to organise plant doctor training and stakeholder meetings, procure materials for selected districts and carry out monitoring. The Department also offered their diagnostic facilities as a referral laboratory for the plant clinics. In 2011, the Department trained 40 agricultural inspectors in the principles of field diagnostics and plant clinic operation. The idea was to build capacity to provide on-the-spot technical backstopping and supervision to plant clinic staff, to gather plant clinic data, and to convey samples to the laboratory. It was also intended that the inspectors play the strategic role of using the network of plant clinics to identify disease outbreaks more effectively.
Makerere University, in line with its role as a member of the International Plant Diagnostic Network (IPDN), ${ }^{7}$ also offered diagnostic tests to the plant clinics at no cost. Discussions between Makerere, MAAIF and CABI on how to institutionalise and scale up plant doctor training were initiated in 2010-2011. Creating and maintaining a competent plant health workforce was regarded as a key element of plant health system strengthening. In 2011, Makerere University established a 'Plant Health Systems Committee' to coordinate and operationalise the university's training and backstopping activities. $^{8}$

The move towards plant health system thinking became more explicit in 2011. A national stakeholder workshop led to the signing of a 10-point resolution, highlighting the steps needed to expand and improve the plant clinics, strengthening the links between plant health system actors and ensuring long-term sustainability (MAAIF 2011a). In the preamble of the resolution it is stated:

The expansion and consolidation of plant clinics in Uganda require joint commitment and efforts of the many actors involved in crop protection. The plant clinic staff cannot work in isolation. They need to be part of an integrated 'plant health system' where diagnostic

\footnotetext{
${ }^{7}$ IPDN was set up to build diagnostic capacity and strengthen the linkages between diagnostic laboratories and potential users, i.e., farmers and extension workers: http://www.intpdn.org/

${ }^{8}$ In 2013, Makerere University conducted plant doctor training for 90 students.
} 
expertise, research, agricultural input supply and pest and disease information systems work together to deliver responsive, quality services. Today, many of these services and knowledge providers are disconnected.

\section{The plant health system framework}

Literature provides several frameworks and indicators that can be used for designing and assessing human health systems (Murray and Frenk 2000; Shengelia et al. 2005; WHO 2007; Backman et al. 2008; Kruk and Freedman 2008). After reviewing literature on health system frameworks, Shakarishvili et al. (2010) conclude that despite variations regarding scope, focus and categorization, there is a considerable overlap among the frameworks in terms of system components and performance indicators.

In 2007, the WHO established a health system framework based on six basic 'building blocks', namely: service delivery, health workforce, information, medical products and technologies, financing and policy, and leadership and governance. We adapted this framework to plant health, assuming that these system components are equally critical to attaining outcomes in plant health (Fig. 2). Although there obviously are major differences between human and plant health there are also many analogies that make such an assumption plausible: provider-client interactions, delivery systems for services and inputs (drugs), availability of skilled work force, stewardship etc. The WHO advises that the framework be applied flexibly since 'health systems are highly context-specific, there is no single set of best practices that can be put forward as a model for improved performance. But health systems that function well have certain shared characteristics.' Emphasising the benefits of using such a framework, Shakarishvili et al. (2010) argue that 'the building block approach is a useful means for locating, describing and classifying health system constraints, for identifying where and why investments are needed, what will happen as a result, and by what means the change can be monitored.'

Our study applied the framework at the plant clinic level the primary level of plant healthcare delivery and a key target for current efforts of Plantwise ${ }^{9}$ to strengthen plant health systems. In line with broadly accepted practice (WHO 2007; Kruk and Freedman 2008; Shakarishvili et al. 2010) and building on previous research on plant clinic quality assessment (Danielsen and Kelly 2010), coverage, access and quality of plant healthcare were adopted as performance indicators (Fig. 2). The variables defined for system components and clinic performance are presented in Table 1. Although 'access' is a complex feature influenced by many factors including

\footnotetext{
${ }^{9}$ Our analysis covers the period until the Plantwise launch in Uganda in 2012
}

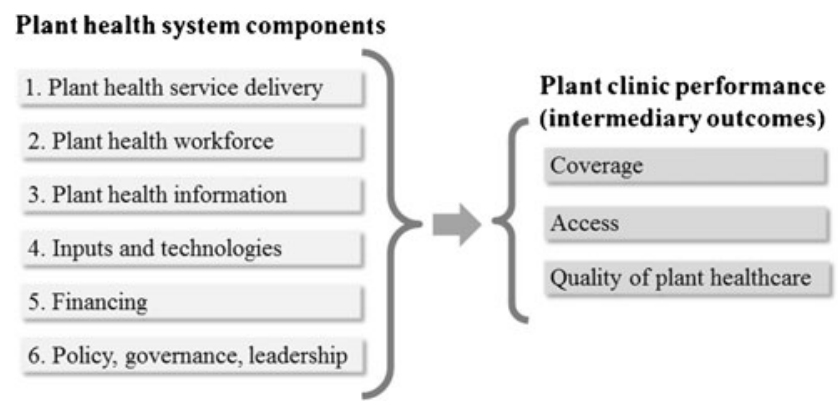

Fig. 2 Plant health system framework (modified after WHO 2007)

geographic distance, location, literacy, wealth and social norms, 'plant clinic regularity' and 'timeliness' were deemed appropriate partial proxies for access, since the availability and consistency of clinic services are likely to influence utilization rates (Dash et al. 2008).

\section{Materials and methods}

A comparative study of plant clinics was carried out between July 2010 and September 2011 in the 12 districts where plant clinics were operating at that time (eastern, central and western Uganda). Plant clinics were implemented by three nongovernmental organisations (NGOs) (Self Help Africa (SHA), Soroti Catholic Diocese Integrated Development Organisation (Socadido) and Rwenzori Information Center Network (RicNet)) and five district local governments (LGs) (Mukono, Buikwe, Hoima, Soroti and Serere districts) (Table 2). The NGOs operated in more than one district. Plant clinic sessions were held at 36 different locations at varying intervals. Most clinics were scheduled to operate fortnightly, usually from a market place. Hoima LG and SHA adopted a mobile scheme to expand sub-county coverage.

In some districts LGs and NGOs operated independently, whilst in others they implemented plant clinics jointly. In Kumi, Ngora and Bukedea districts LG staff were seconded to SHA Kumi through a formal arrangement, while in Soroti and Serere the involvement of LG staff with Socadido was more sporadic and informal. In these latter two districts, the LGs also ran some plant clinics outside the LG-NGO partnership.

The unit of observation was the plant clinic and the unit of analysis the plant clinic organisation's area of operation. The implementing NGOs and LGs used their geographically mandated area as the unit for supporting and administering plant clinic activities, which in some cases meant more than one district (SHA Kumi, Socadido, RicNet) (Table 2). The plant clinic designations listed in Table 2 comprise the aggregated plant clinic activities implemented by each of the nine organisations in their mandated district(s). SHA had two independent operations in Kayunga and Kumi districts, respectively, and was therefore treated as two separate organisations. 
Table 1 Variables used to assess plant health system components and plant clinic performance

\begin{tabular}{ll}
\hline Attribute & Variable \\
\hline $\begin{array}{ll}\text { Plant health system component } \\
\text { 1. Plant health service delivery }\end{array}$ & $\begin{array}{c}\text { Materials and logistics; publicity; record keeping; monitoring } \\
\text { and reporting; technical backstopping }\end{array}$ \\
Plant clinic staffing; skill level; retention; incentives and motivation \\
$\begin{array}{l}\text { 2. Plant health workforce } \\
\text { 3. Plant health information }\end{array}$ & $\begin{array}{c}\text { Access; availability; quality } \\
\text { 4. Input supply and technologies }\end{array}$ \\
$\begin{array}{l}\text { 5. Financing } \\
\text { 6. Policy, governance and leadership }\end{array}$ & $\begin{array}{c}\text { Policy and governance framework; local level support/ } \\
\text { leadership; central level support/leadership }\end{array}$ \\
Plant clinic performance indicator & Client attendance; plant clinic catchment area \\
1. Coverage & Plant clinic regularity; timeliness; gender equity; \\
2. Access & geographical distance \\
3. Quality of plant healthcare & Quality of diagnosis; efficacy of advice; feasibility of advice \\
\hline
\end{tabular}

Qualitative and quantitative data were collected through a survey that combined questionnaires, key informant interviews, review of all plant clinic query records from the 14month study period, direct observation of plant clinics and GPS mapping. Key informants included plant clinic staff and coordinators; political, administrative and technical leaders of LGs; officials from the Ministry of Agriculture, Animal Industries and Fisheries (MAAIF), National Agricultural Advisory Services (NAADS), National Agricultural Research Institute (NARO) and non-governmental organisations (NGO); researchers from Makerere University; and representatives from international development organisations and donor agencies. Table 3 lists the data collections methods and what they were used for.

Quality of plant healthcare was assessed using the plant clinic record analysis method developed by Danielsen et al. (2013b). Using this method, the validity of diagnoses was assessed for the 10 most frequently presented crops. The efficacy of advice was assessed for the five most frequently presented problems: cassava brown streak disease, banana bacterial wilt, groundnut rosette, orange leaf miner and coffee wilt disease. These five problems represented more than $25 \%$ of all farmer queries.

Data from the qualitative interviews were analysed using content analysis techniques. SPSS (Statistical Package for Social Science Version 16.0) and Microsoft Office Excel 2007 were used to generate descriptive statistics for the quantitative data; ArcGIS Desktop 10 for mapping plant clinic user origin; and QGIS 2.2 for calculating clinic-client distances and clinic catchments areas. Due to the limitations of the plant clinic record data (i.e., differences in lengths of plant clinic operational periods) performance results derived from these data were presented as descriptive statistics only.

For overall comparison of plant clinics we established a 5 point scale: 1-poor; 2-inadequate; 3-fair; 4-good; 5-excellent, and scored the variables in Table 1 based on the evidence
Table 2 Districts, plant clinics and implementing organisations included in the study

\begin{tabular}{|c|c|c|c|}
\hline Region & District & Plant clinic designation $^{\mathrm{a}}$ & Implementing organisation $^{\mathrm{b}}$ \\
\hline \multirow[t]{3}{*}{ Central } & Mukono & MU-LG (4) & LG \\
\hline & Buikwe & BU-LG (3) & LG \\
\hline & Kayunga & KA-SHA (7) & SHA Kayunga \\
\hline \multirow[t]{4}{*}{ Eastern } & Kumi, Bukedea, Ngora & KU-SHA (3) & SHA Kumi in collaboration with LG \\
\hline & Soroti, Serere, Katakwi & SOCA (3) & Socadido (with occasional LG support) \\
\hline & Soroti & SO-LG (1) & $\mathrm{LG}$ \\
\hline & Serere & SE-LG (1) & LG \\
\hline \multirow[t]{2}{*}{ Western } & Hoima & HO-LG (9) & LG \\
\hline & Kasese, Bundibugyo & RIC (5) & RicNet \\
\hline
\end{tabular}

${ }^{a}$ Covers aggregated plant clinic activities within the mandated district(s). The numbers in bracket indicate the number of locations where plant clinic activities took place

${ }^{\mathrm{b}} L G$ Local Government, SHA Self Help Africa (NGO), Socadido Soroti Catholic Diocese Integrated Development Organisation (NGO); RicNet Rwenzori Information Center Network (NGO) 
Table 3 Data collection methods used

\begin{tabular}{|c|c|c|}
\hline Method & Cases & Component/indicator assessed \\
\hline $\begin{array}{l}\text { 1. Questionnaire survey among plant } \\
\text { clinic staff and coordinators }\end{array}$ & 47 respondents $^{\mathrm{b}}$ & All PHS ${ }^{\mathrm{a}}$ components \\
\hline 2. Key-informant interviews & 34 respondents $^{\mathrm{b}}$ & All PHS components \\
\hline 3. Review of plant clinic records & 2,598 query records & $\begin{array}{l}\text { Access; Coverage; Quality of } \\
\text { plant healthcare }\end{array}$ \\
\hline 4. Direct observation & 6 plant clinics & $\begin{array}{l}\text { Plant clinic service delivery; } \\
\text { Input supply; Access }\end{array}$ \\
\hline $\begin{array}{l}\text { 5. Collection of GPS coordinates of } \\
\text { origin of clinic users }\end{array}$ & 12 districts & Coverage \\
\hline
\end{tabular}

collected. Some of the variables could not be scored within the frame of the present study, for example quality of inputs and plant health information and feasibility of advice. With regard to skill level of plant clinic staff, the only distinction made was between extension workers and lead farmers. The average scores for each system component and performance indicator were calculated and used to create 'spider web' diagrams. Plant clinics with similar patterns (max. \pm 0.3 deviation of averages) were grouped for visual comparison. HO-LG was not included in this part of the analysis due to insufficient data on several variables. The spider web diagrams represent a rough picture of the situation as assessed by the authors.

\section{Results}

The 'spider web' diagrams presented in Fig. 3 are graphical summaries of the findings. The average scores of the variables in Table 1 (scores not shown) were plotted against plant clinics: Fig. 3a by plant health system component and Fig $3 b$ by performance indicator.

The plant clinics fell into five groups with slight variations in ranks between the two graphs, indicating a fairly good overall match between system components and performance. KA-SHA and KU-SHA were rated highest, MU-LG and BULG in the middle and the rest were rated lowest. In most cases, the plant health system components and performance indicators were rated as 'fair' or lower $(\leq 3)$ suggesting general systemic weaknesses. In the following narrative we summarise the key findings that led to these results.

\section{Plant health system components}

\section{Plant health service delivery}

Overall, the quality of plant health service delivery was rated as low $(<3.0)$. KU-SHA and KA-SHA's higher score was attributed to relatively better logistics, publicity and record keeping. Plant clinic staff faced logistical challenges, particularly regarding staff mobilisation and transportation, and storage of materials, which constrained their compliance with planned schedules. Publicity was frequently cited by clinic staff (43\%) as a weak point in service delivery. Often
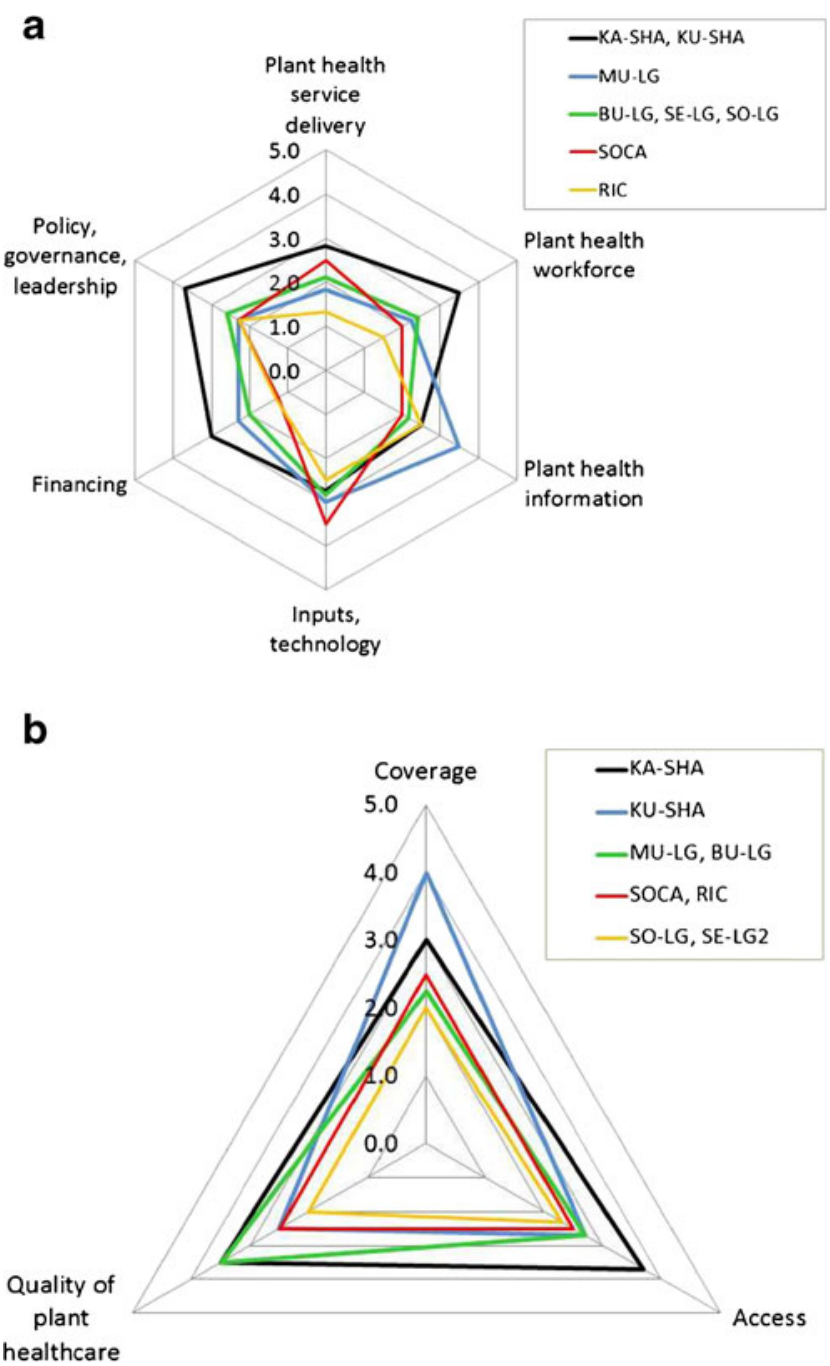

Fig. 3 'Spider web' presentation of plant clinics by (a) plant health system component and (b) performance indicator. Scale: 1-poor; 2 inadequate; 3-fair; 4-good; 5-excellent 
clients were only alerted to the presence of a plant clinic by the clinic tent and banner on arrival at the market. Some promising approaches to the problem included the use of radio and megaphone messages which were associated with a high turnout in the SHA's areas of operation.

While plant clinic record keeping was better than in the pilot phase (Danielsen and Mutebi 2010), major weaknesses remained ubiquitous. Lack of clarity about procedures, actor roles and responsibilities constrained effective management and use of the clinic data. Electronic recording, for example, was only done by staff of SHA and Socadido who had received targeted training. Likewise, plant clinic monitoring was done sporadically and without well-defined purpose, standards and follow up procedures. Most plant clinic staff regarded follow-up by and feedback from their supervisors, MAAIF and CABI, as inadequate. Monitoring was particularly challenging for RicNet due to the geographical dispersion of plant clinic activities and staff.

Little progress was made in establishing a formal referral system for dispatching samples from the plant clinics to MAAIF and Makerere University. None of the trained agricultural inspectors, for instance, had been in contact with the plant clinics. Only one sample had been sent from the SOCA clinic to MAAIF while some six plant samples were sent to Makerere University from KA-SHA. Some of the key issues are summed up in the following observation by a senior official from MAAIF: 'The plant doctors don't know how to send the samples. We are looking at using the post buses to refer samples from the plant clinics to us. MAAIF would pay the costs from the DSIP budget. The referral system needs to be operationalised.'

\section{Plant health workforce}

The plant health workforce component was rated between 3.5 (KU-SHA, KA-SHA) and 1.5 (RIC) with differences mainly prevalent in staff numbers, retention and incentives. A typical plant clinic session was manned by 1 or 2 plant doctors assisted by 1 or 2 nurses/nursing aids. Notably only KUSHA was able to mobilise teams of 4 plant doctors and 3 to 4 nurses that rotated among four clinic locations. KU-SHA was run with the help of seconded LG staff while RIC used lead farmers as plant doctors and nurses. More than half the plant clinic staff and coordinators noted that scarcity of plant doctors and workload from competing assignments were obstacles to regular clinic operation.

These staffing constraints were compounded by relatively high staff turnover. Nearly half of the 86 persons who had received some form of plant doctor training from CABI or MAAIF since 2006 were no longer involved in plant clinic activities. On the positive side, the challenges of the job, the direct interaction with farmers and the plant doctor courses served as key motivators for clinic staff. As one Kumi based plant doctor explained: 'As a plant doctor you should be able to answer ANY question. It is challenging and rewarding.' A major disincentive, however, was a perception of insufficient remuneration. Allowances were viewed as too small and/or erratic. This was particularly problematic for staff who had to pay for transportation and materials out of their own pockets. The problem of lack of staff incentives was also recognised by the plant clinic organisations. In the words of one District NAADS Coordinator: 'The incentives are few and the general work load is high. Farmers complain that the plant clinic doesn't open as announced. All that affects staff morale'. Only SHA had sufficient budget to cover the field allowances in the period.

\section{Plant health information}

With the exception of MU-LG, we found plant health information access and use to be relatively low among the plant clinics. The majority of plant clinic staff and coordinators mentioned MAAIF, National Agricultural Research Organisation (NARO), internet sources, NAADS/LG and CABI, in that order of importance, as their main sources of information on pests and diseases.

About $55 \%$ of the interviewed plant clinic staff had access to internet, most of them from visiting internet cafés or using personal modems at least once a week. However, few among this relatively high proportion of internet users actively sought information on plant health. Connections were generally slow and most staff had to pay their own internet services bills. It is noteworthy that none of the interviewed plant doctors mentioned any of the many initiatives in Uganda promoting usage of internet and mobile phones for improving extension workers' and farmers' access to agricultural information.

One of MAAIF's key interests in plant clinics derives from the opportunity to improve the national plant health information system through systematic collection of query data from the plant clinics. By the close of the study period no progress had been made in setting up a system to gather, process, analyse and use plant clinic data. There were no agreements and procedures in place. In the districts there was an expectation that MAAIF or CABI would provide the necessary guidance. Calling for more clarity and action, a RicNet coordinator observed: 'We need a common platform to share and use the information. What problems turn up? What to do with it? We need a system to refer to, to take action.' Likewise, a senior MAAIF official referred to the problems rooted in an unsupportive attitude towards data collection and sharing: 'We are trying to improve [data capture]. It has not been motivating work. There is no remuneration, no recognition for typing up data. Communication and exchange of information are weak. We really have to grow out of the notion that by keeping information to ourselves we are better than others.' 
Input supply

All plant clinics were rated between 2.5 and 3.0 with regard to input supply (availability and access) except SOCA (3.5) that had a small stall of selected quality inputs for sale at the plant clinic. Initially the plant clinics were only intended to provide information and advice on plant health, but we found an increasing perception of the need to link the clinics more directly to agro-inputs sources. As one Local Council Chairman explained, "The clients expect to have access to inputs at the plant clinic. They need the drugs; the advice alone is not enough. They remain with the feeling that they are not served.This situation reflects the broader national context of low use of quality inputs associated with limited access and availability and high costs of products, as well as pervasiveness of fake products. The high prevalence of counterfeit agro-inputs on the market frustrated many plant clinic organisations. As noted by a SHA coordinator: "Seed certification and quality control are a big problem. There is a lot of fake seed and agrochemicals around and the law enforcement is weak."

Some of the plant clinics had endeavoured to respond to clients' expectations by including displays of a few inputs. RicNet saw the integration of input sale into its plant clinic activities as a promising business model for the future (interview with RicNet coordinator). The model was being tried in Kasese district, where a plant clinic was run by a plant doctor who was also a certified input dealer. Creating links between plant clinics and reliable agro-input suppliers, however, was mentioned as a controversial issue. On the one hand, farmers need better access to quality inputs. On the other hand, if plant doctors have commercial interests in giving input-based advice, or are perceived as favouring certain input dealers over others, it may bias the advice given and eventually undermine clients' trust in the service.

\section{Financing}

Virtually all organisations mentioned inadequate operational funds for logistics, publicity, materials and field allowances as a major constraint to maintaining regular operations. KUSHA and KA-SHA scored higher (3.0) than the other plant clinics due to SHA's more pro-active funding policy. Over the study period, CABI remained a key source of funding even as the funding base for the plant clinics expanded. Most organisations received a small start-up grant from CABI to cover the cost of materials and initial operations. Various strategies were adopted to help sustain plant clinic operations, but with varying success: some managed to sustain intermittent clinic sessions whilst others ceased operations completely. MAAIF's Production and Marketing Grant (PMG), for example, helped to fund some plant clinic sessions in Mukono, Buikwe and Hoima districts. According to a senior Hoima LG official, the local council sought to institutionalise the plant clinics from the beginning by writing them into the medium and long-term plans for the district. Core funds from Irish Aid were used to cover SHA's clinic operational costs. RicNet and Socadido, on the other hand, were not able to secure supplementary funding, leading to a sharp decline in plant clinic activities once the CABI grant ran out in 2011.

The inclusion of plant clinics in the DSIP gave formal endorsement for government funding. Approximately USD 20,000 was allocated for 2011/12 to plant doctor training, provision of basic plant clinic tool kits, monitoring visits and technical support/backstopping (MAAIF 2011b). Because of delays in the release of DSIP funds and MAAIF's bureaucratic procurement system, however, the starter kits had not yet been delivered to the selected districts by February 2012 (interview with senior MAAIF official). Additionally, due to NAADS's funding levels and inflexibility, it had not been possible for districts to tap into NAADS operational funds so as to cover plant clinic running costs. The 'non-NAADS' ${ }^{10}$ LG budgets were even more restricted.

\section{Policy, governance and leadership}

Apart from SHA-KA and SHA-KU, all plant clinics were rated low on policy, governance and leadership. Differences were mainly observed in local level leadership. Whereas the integration of plant clinics into government policy was deemed by many informants as a significant step towards investing in plant clinics and creating a more coherent plant health system, it was evident that the plant clinics expanded in a loose and unregulated way. It was not clear, for example, who would be charged with quality assurance and data management. The roles and authority of the different actors were not clear. As pointed out by one of the coordinators, 'The planning is a bit floating. The clinics are a new concept; we need clearer directions on how to operate'. The governance problem was multi-faceted. For one thing, there was no consensus on whether the plant clinics belonged under the NAADS or the 'non-NAADS' domains of the extension system. In addition, MAAIF did not have the critical human and financial resources required to undertake the leading role. Further challenges came in 2010/2011 as a result of the turbulence created by national elections, a new district reform and the initiation of a new phase of NAADS (Danielsen et al. 2014). All this limited plant clinic regularity and consolidation.

Responses to the above challenges by the plant clinic organisations varied significantly. Hoima, for example,

\footnotetext{
${ }^{10}$ Agricultural extension is decentralised in Uganda and implemented by local governments through two parallel mechanisms: the NAADS programme, which provides advisory services and inputs to farmer groups for selected commodities, and the 'non-NAADS' extension activities, which cover cross-cutting services such as regulation of agricultural inputs, pest and disease control, general extension, planning and statistics. In 2014, the Government of Uganda initiated a new agricultural extension reform.
} 
proactively sought to be self-sustaining by securing political support and operational funds from the LG. SHA opted for engaging political, technical and administrative leaders at district level as well as civil society representatives to expand the base for plant clinic sustainability. Several informants highlighted the importance of engaging local leaders to ensure that the clinics became firmly anchored in the communities.

The challenges of leadership were also recognised at the national level. Following the signing of 'Resolution on plant health clinics in Uganda' at the national plant health stakeholder meeting in 2011 (MAAIF 2011a), some fundamental questions remained about governance and leadership, such as this one raised by a senior lecturer from Makerere: 'How do you follow up on the workshop resolution when there is no constituency around the plant clinics, no formal structure? Where will the leadership come from?'

\section{Plant clinic performance}

\section{Coverage}

In total, the plant clinics received 2,578 queries on 53 crops from 2,049 clients (Table 4). KA-SHA, KU-SHA and HO-LG accounted for $61 \%$ of all queries. Their plant clinic sessions were relatively better attended, with an average of 25 to 40 queries per session compared to 15 for SO-LG and between 4 and 8 queries per session for the rest. This better attendance at the SHA and Hoima plant clinics was largely attributed by staff to the targeted publicity campaigns held prior to each session. The number of sessions per aggregated plant clinic varied from 5 (SO-LG) to 43 (RIC), reflecting differences in starting dates, number of plant clinic locations and regularity of operations.

The plant clinic catchment areas (perimeter of the outer parishes around plant clinic location minus outliers) varied from $37 \mathrm{~km}^{2}$ (RIC) to $172 \mathrm{~km}^{2}$ (KU-SHA) (Table 5).
The catchment areas in the eastern region are illustrated in Fig. 4 as an example. The map shows greater parish coverage and higher client density in Kumi, Bukedea and Ngora districts (KU-SHA plant clinic) compared to Soroti, Serere and Katakwi districts (SOCA, SO-LG and SE-LG plant clinics). This correlates well with the higher client turnout at the KUSHA clinic. The catchment areas overlap in some districts.

\section{Access}

KA-SHA's higher score on access compared to the other plant clinics (Fig. 3b) is attributed to better plant clinic regularity (data not shown) and a higher proportion of female clients (Table 4). Overall, compliance with the planned schedules fluctuated heavily over time. From late 2010 to early 2011, there were almost no LG plant clinic operations. By mid-2011, BU-LG and MU-LG had resumed regular clinic operation as programmed while SE-LG and SO-LG were still having difficulties in complying with the established schedule. After the first quarter of 2011, the RIC and SOCA operations dwindled as the CABI grant ran out. Plant clinic staff and coordinators attributed the limited compliance with planned schedules to staff scarcity, work overload, emergence of unplanned activities, insufficient operational funds and the turbulent political environment referred to above.

Some plant clinics opened on time and kept client waiting time short. There were also instances where opening delayed for 1.5 to $5.5 \mathrm{~h}$, sometimes prompting farmers to abandon the clinic sites. Once the clinic opened, time management tended to be influenced by the client/staff ratio and staff motivation. Adequate staffing and a positive staff attitude, for example, made it possible to attend to several clients simultaneously and thus make up for the late start (visit to plant clinic in Kumi district 8th September 2011).
Table 4 Plant clinic attendance in Uganda from July 2010 to Sept 2011

\begin{tabular}{lccl}
\hline $\begin{array}{l}\text { Plant } \\
\text { clinic }\end{array}$ & $\begin{array}{l}\text { \% queries received (total } \\
n=2,578)\end{array}$ & $\begin{array}{l}\text { Av. queries per clinic } \\
\text { session }^{\text {a }}\end{array}$ & $\begin{array}{l}\text { \% women users (total } \\
n=2,049)\end{array}$ \\
\hline MU-LG & 5.4 & $4(32)$ & 37 \\
BU-LG & 8.3 & $5(40)$ & 35 \\
KA-SHA & 18.7 & $25(19)$ & 44 \\
KU-SHA & 23.3 & $27(22)$ & 18 \\
SE-LG & 2.5 & $8(8)$ & 12 \\
SO-LG & 2.8 & $15(5)$ & 15 \\
SOCA & 7.2 & $7(25)$ & 23 \\
HO-LG & 19.0 & $40(10)$ & 41 \\
RIC & 12.8 & $8(43)$ & 53 \\
Total/ av. & 100 & $13(204)$ & 33 \\
\hline
\end{tabular}

Source: Plant clinic records

${ }^{a}$ The numbers in bracket refer to the number of plant clinic sessions held in the study period 
Table 5 Geographical plant clinic coverage and clinic-client distance

\begin{tabular}{llc}
\hline Plant clinic & Plant clinic catchment area $\left(\mathrm{km}^{2}\right)^{\mathrm{b}}$ & Av. weighted distance to plant clinic $(\mathrm{km})^{\mathrm{c}}$ \\
\hline MU-LG & 46 & 3.7 \\
BU-LG & 122 & 7.7 \\
KA-SHA & 55 & 5.7 \\
KU-SHA & 172 & 16.5 \\
SE-LG & 93 & 7.0 \\
SO-LG & 82 & 10.0 \\
SOCA & 128 & 14.3 \\
HO-LG & - & - \\
RIC & 37 & 5.4 \\
Total/ av. & Av. 91.9 & Av. 6.6 \\
\hline
\end{tabular}

Source: Plant clinic records and GPS coordinates

${ }^{\text {a }}$ Information on client origins from HO-LG was incomplete

${ }^{\mathrm{b}}$ Average catchment area in case of multiple locations

${ }^{\mathrm{c}}$ Averages weighted against clients attended
Women's attendance varied substantially among organisations (Table 4). Overall, $33 \%$ of the clients were female. Among the organizations, however, the proportion was as low as $12-18 \%$ (KU-SHA, SO-LG and SE-LG) rising to 41-53\% (KA-SHA, HO-LG and RIC), indicating differences in equity in access. The average distance travelled to reach a plant clinic was $6.6 \mathrm{~km}$, varying from $3.7 \mathrm{~km}$ (MU-LG) to $16.5 \mathrm{~km}$ (KU-SHA) (Table 5). Twenty seven percent (27\%) of the plant doctors believed that the distance to the clinics prevented farmers from attending.
Fig. 4 Plant clinic catchments areas in eastern Uganda. The dots indicate parishes from where the clients came: Orange dots $\leq 7$ clients per parish; Red dots $>7$ clients per parish

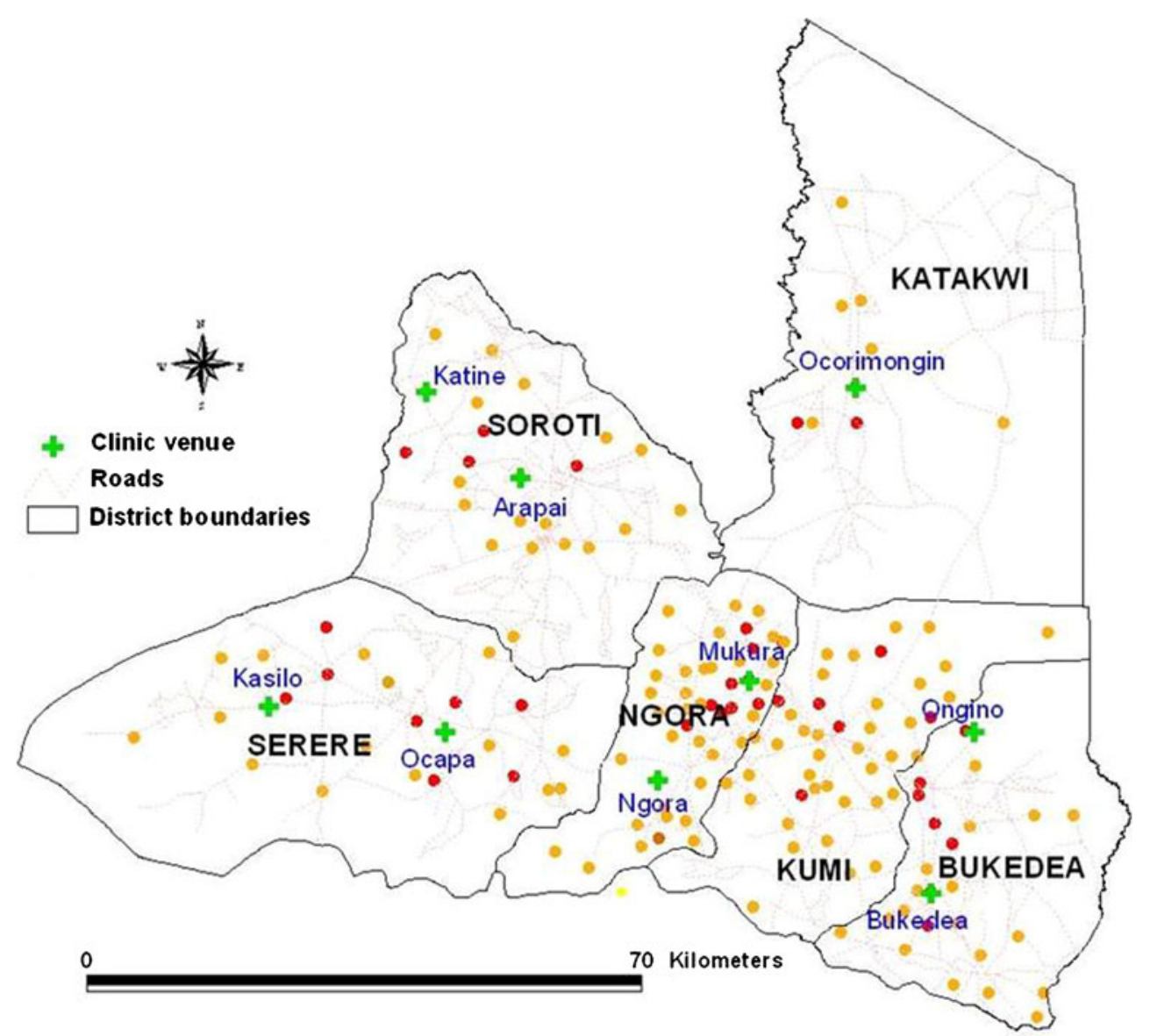


Table 6 Validation of plant health diagnoses ${ }^{\mathrm{a}}$ for the overall top-10 crops $^{\mathrm{b}}$

\begin{tabular}{lllll}
\hline \multirow{2}{*}{ Plant clinic } & \multicolumn{4}{c}{ Validation of diagnosis } \\
\cline { 3 - 5 } & Queries & \% complete & \% partial & \% reject \\
\hline MU-LG & 152 & 49.3 & 35.5 & 15.1 \\
BU-LG & 103 & 38.8 & 40.8 & 20.4 \\
KA-SHA & 402 & 35.1 & 48.8 & 16.2 \\
KU-SHA & 395 & 21.0 & 54.2 & 24.3 \\
SE-LG & 47 & 6.4 & 48.9 & 44.7 \\
SO-LG & 67 & 7.5 & 14.9 & 77.6 \\
SOCA & 138 & 8.7 & 76.1 & 15.2 \\
HO-LG & 257 & 19.8 & 57.2 & 23.0 \\
RIC & 87 & 20.7 & 8.0 & 71.3 \\
Total & 1,648 & 26.0 & 48.5 & 25.5 \\
\hline
\end{tabular}

Source: Plant clinic records

${ }^{\text {a }}$ Validation method according to Danielsen et al. (2013b)

${ }^{\mathrm{b}}$ Cassava, Orange, Banana, Groundnut, Tomato, Coffee, Bean, Maize, Sweet potato, Rice (data not shown)

\section{Quality of plant healthcare}

The assessment of quality of diagnoses and advice was based on information available from plant clinic records. The proportion of valid ('complete') diagnoses varied substantially between plant clinics (Table 6). BU-LG, MU-LG and KASHA had the highest complete validation rates (35.1$49.3 \%$ ) and some of the lowest rejection rates. The low complete validation rates by SO-LG, SE-LG and SOCA (6.4$8.7 \%$ ) can largely be explained by the problems with orange

Table 7 Efficacy of advice ${ }^{\text {a }}$ given by plant clinic organisations for the five main overall plant health problems ${ }^{\mathrm{b}}$

\begin{tabular}{lllcc} 
Plant clinic & \# queries & \multicolumn{2}{c}{ Efficacy of advice by organisation (\% queries) } \\
\cline { 3 - 5 } & & 'Best practice' & Partially effective & Ineffective \\
\hline MU-LG & 43 & 7.0 & 93.0 & 0.0 \\
BU-LG & 70 & 0.0 & 100 & 0.0 \\
KA-SHA & 225 & 6.2 & 90.7 & 3.1 \\
KU-SHA & 150 & 0.0 & 64.7 & 35.3 \\
SE-LG & 11 & 9.1 & 54.5 & 36.4 \\
SO-LG & 18 & 0.0 & 55.6 & 44.4 \\
SOCA & 42 & 0.0 & 88.1 & 11.9 \\
HO-LG & 55 & 0.0 & 98.2 & 1.8 \\
RIC & 48 & 0.0 & 100 & 0.0 \\
Total & 662 & 2.7 & 85.5 & 11.8
\end{tabular}

Source: Plant clinic records

${ }^{a}$ Method according to Danielsen et al. (2013b)

${ }^{\mathrm{b}}$ Cassava brown streak disease, Banana bacterial wilt, Groundnut rosette, Orange leaf miner, Coffee wilt disease (data not shown) leaf miner diagnoses (data not shown). RIC had a high rejection rate $(71.3 \%)$ because many records lacked a symptom description.

The efficacy of the advice given was assessed against currently recommended control options for Uganda. The proportion of 'best practice' advice was low for all organisations, ranging from 0 to $9.1 \%$ with an overall average of $2.7 \%$ (Table 7). The overall efficacy of advice among the eastern region plant clinics (KU-SHA, SOCA, SO-LG and SE-LG) was largely reduced by the ineffective advice given on orange leaf miner, the main pest in the region (data not shown). For the other plant clinics most advice was rated as 'partially effective' $(90.7-100 \%)$.

\section{Discussion}

\section{What does the framework tell about plant clinics and systems in Uganda?}

Plant clinic performance The study shows that plant clinics have the potential to cover considerable geographical areas and address a broad range of farmer demand for plant health advice, thus complementing existing extension approaches used in Uganda. However, it is unclear whether farmers' access to plant clinics was generally satisfactory. For example, we cannot say from the results to what extent the distances to the plant clinics influenced farmers' access (Table 5). Up to $16 \mathrm{~km}$ appear to be a long way to reach a plant clinic, yet the farmers may have travelled that distance anyway for other purposes, for example to visit a market, with the plant clinic visit as an added bonus. The low participation of women in some districts (Table 4) raises questions about the appropriateness of the timing and location of the clinics. Inconsistent plant clinic operations coupled with inadequate publicity led to very low plant clinic attendance in some districts (Table 4), rendering the investment questionable in such cases. KUSHA, KA-SHA and HO-LG had considerably higher farmer attendance than the other clinics. Feedback from male and female farmers is essential to shed light on the issues that influence their access to the plant clinics and whether there are any biases towards or against particular types of farmers and communities. The joint NGO-LG model used by KUSHA had several benefits. By combining the financial resources and organisational skills of SHA with the technical capacity and public sector anchoring of the LGs, the plant clinic operations became more flexible and consistent compared to the 'single actor' clinics. This finding is in line with Bashaasha et al. (2011) who observed that public sector-NGO collaboration, which is common in Uganda, has the potential to enhance institutional resilience and thereby improve local service delivery. Sseguya et al. (2012) also found that close collaboration between LGs and NGOs enhanced community 
members' trust in government agencies. An often cited disadvantage of NGOs, however, is that they tend to depend on short term project funding that is vulnerable to erratic changes in funder priorities. Our study illustrated both the strengths and the weaknesses of NGOs whose plant clinic performance was at both ends of the scale.

The effects of systems factors The plant health system framework helped identify a number of systemic weaknesses that affected plant clinic performance and limited the scope of plant health system strengthening. Proactive leadership, as seen in SHA and Hoima LG for instance, can make up for some of these weaknesses, while other constraints, for example the unfavourable policy environment, affected all equally. The agricultural sector in Uganda is fragmented and characterised by an unstable policy environment, lack of institutional stability and weak stewardship (Rwamigisa et al. 2013). This fragmentation led to several constraints, making it difficult for the districts to institutionalise the plant clinics and for MAAIF and other key actors to coordinate actions effectively. Despite the goodwill of MAAIF and Makerere University, the establishment of a functional backstopping system remained a major organisational challenge (procedures, logistics and communication). Like many developing countries, Uganda faces the paradox of low utilisation of existing laboratory services and other technical capacity (Smith et al. 2008; AII 2010). Insufficient financing, high staff turnover and staff scarcity were general threats to plant clinic stability. The workforce shortage is likely to continue as scarcity of extension workers is a general problem in Uganda (Bashaasha et al. 2011).

Although all recognised that the plant clinic data have great potential to improve decision making at district and central levels, it turned out to be difficult to make reality of the intentions. The limited progress with the establishment of a system to handle and use plant clinic data reflects common problems with frail and disjointed information management in Uganda (AII 2010; MAAIF 2010). Also in human health, fragmented and weak health information management systems are general problems in many countries (Oliveira-Cruz et al. 2003; Braa et al. 2012). One of the causes of fragmentation is the existence of many parallel project-based information systems, often set up by donors to meet their needs for project data. Any attempt to establish a better plant health information system must address the fundamental issues of ownership and organisational fit to avoid further fragmentation.

The overall weaknesses identified in this study were surprisingly similar to those frequently found in human health in low-income countries: shortage of qualified staff, insufficient technical guidance and supervision, weak systems for planning and management, weak drug supply systems, reliance on donor funds, government bureaucracy, poor communication and transport infrastructure (Hanson et al. 2003; Oliveira-Cruz et al. 2003).
Implications for plant health system strengthening There is still limited experience with designing and testing interventions to strengthen plant health systems, but extensive experience from human health can help guide the process. According to Shakarishvili et al. (2010) and Sandall et al. (2011) interventions need to address the root causes of performance gaps and take account of the institutions' absorptive capacity, human and financial resources as well as the specific organisational context. Solutions must be context-specific. As Mills et al. (2011) observed, plant health policy is multidimensional in nature and implementation must be well grounded in reality with responsibility shared among key actors. Several studies have found that health system strengthening is enabled by factors such as better coordination (including between donors), synergies between vertical and horizontal programmes, leadership and management capacity, capacity for effective service delivery, clear lines of accountability and evidence base for assessment (Balabanova et al. 2010; Pallas et al. 2012). Based on the findings presented here it is reasonable to conclude that these conditions are applicable to plant health system strengthening as well, both in Uganda and elsewhere.

\section{Applicability of the plant health system framework}

In this study we compared different plant clinics and demonstrated the results as spider web diagrams as a way to test the framework. The advantage of using a quantitative scale was that it gave an overall easy-to-identify picture of the strengths and weaknesses of each plant clinic and how they influence performance. Yet, the ratings should be treated with some caution though, since the study was based on a relatively limited data set. More comprehensive information is needed to assess all the proposed variables adequately (Table 1), to identify their relative importance and also to test the replicability of the ratings. Despite these limitations, the results give an indication of trends that can be used to identify areas that need to be addressed.

A visual comparison of the two spider webs (Fig. 3) shows a fairly close match between the plant clinic ratings in terms of performance and system components, suggesting that the plant health system components to a large extent can help explain plant clinic performance. The differences between the plant clinics observed in Fig. 3a were mainly attributed to differences in context (funds, staff, policies) and behaviour (leadership, management). SHA's proactive approach to plant clinic investment, networking and management appears to have resulted in higher performance ratings. Likewise, the lower performance of SO-LG, SE-LG, SOCA and RIC corresponded to lower scores for most of the system components.

Quality of plant healthcare was not clearly related to any particular system component, e.g., staff skills, access to plant health information, technical backstopping or agro-inputs. This may partially be explained by the limitations of the data regarding staff skills and quality of plant healthcare. In 
addition, quality assessment based on five plant health problems is insufficient to draw broad conclusions about the quality of advice given at the plant clinics. The analyses of plant clinic records need to be combined with other methods such as skills assessment, field visits and user feedback, including understanding farmers' perceptions and attitudes to risk (Mills et al. 2011). Only the farmers can tell whether the advice they receive is feasible for them (available, affordable and practical) and whether it works.

Although 'regularity and timeliness' are only partial measures for access, they allow us to make inferences about access when other data are limited. It is a reasonable assumption that lack of compliance with planned schedules limits de facto farmers' access to plant clinics. Similar results were reported by Dash et al. (2008) who studied mobile health units in India. A comprehensive assessment of plant clinic access requires more information about the specific context, including feedback from different types of plant clinic users (men and women, age, wealth and ethnic groups, level of education etc.). Optimising access requires knowledge about farmers' behaviour and perceptions.

This study focused on the performance of plant clinics. A broader assessment of plant health system performance requires a more in-depth assessment of other key functions, including diagnostic laboratories, technology, input and information suppliers, extension and regulatory bodies and their interactions. In addition, as suggested by Murray and Frenk (2000), any systemic attempt to understand performance of health systems should be combined with studies of factors that potentially explain it (e.g., stakeholder interactions, organisational cultures, effects of politics).

The plant health system framework needs further testing to explore the full scope of the method, including assessing the relative importance and interactions of the system components, and tracking attributions and longer term outcomes (e.g., improved plant health, resilience and income) over time.

\section{Conclusion}

Plant clinics are a relatively new extension method in Uganda. Many aspects of their operation and performance need to be better understood before they can become an integral part of mainstream extension in Uganda and contribute to system strengthening. Aspects of institutional sustainability of plant clinics as well as demonstration of their cost-effectiveness and benefits to food production and food security also need to be addressed. Using a plant health system framework to analyse the performance of Ugandan plant clinics enabled us to organise multiple issues and to identify key features that affected plant clinics and their context. The framework approach makes it possible to address the complexities related to plant healthcare. By providing insight into specific aspects of plant clinic service delivery, each system component proved useful in identifying intervention points and domains for strengthening the wider plant health system. The framework will undoubtedly evolve as evidence accumulates on plant health systems design, organisation and performance. This study is an example of how experiences and lessons from human health can add value to analysis and practice in the agricultural sector.

Acknowledgments A special thanks goes to staff of Mukono, Buikwe, Hoima, Soroti and Serere Local Governments, Self Help Africa, Socadido, RicNet, Department of Crop Protection of MAAIF, NAADS and NARO for their contributions to the present research. We thank Gabriel Karubanga and Emmanuel Mutebi for assistance with data collection and processing; Josephine Nampijja for creating the map (Fig. 4); Timothy Holmes for calculating distances and catchments areas (Table 5); and Niels Louwaars, Janet Stewart, Niels Ørnbjerg, Jens Aagaard-Hansen for constructive comments to the manuscript. Jens Byskov, Niels Ørnbjerg, Jens Aagaard-Hansen, Maria Vang Johansen, Paul Bloch, Eric Boa, Dannie Romney and Rob Reeder made valuable contributions to the early discussions about plant health systems and synergies with human health. The research was funded by Ministry of Foreign Affairs of Denmark, research grant no. 09-022DBL and the Plantwise programme of $\mathrm{CABI}$, which is financed by a consortium of donors including the UK Department for International Development (DFID), the Swiss Agency for Development and Cooperation (SDC), the European Union, the Ministry of Foreign Affairs of the Netherlands, the Australian Centre for International Agricultural Research (ACIAR), the Ministry of Agriculture of the People's Republic of China, Irish Aid, and the International Fund for Agricultural Development (IFAD).

Open Access This article is distributed under the terms of the Creative Commons Attribution 4.0 International License (http:// creativecommons.org/licenses/by/4.0/), which permits unrestricted use, distribution, and reproduction in any medium, provided you give appropriate credit to the original author(s) and the source, provide a link to the Creative Commons license, and indicate if changes were made.

\section{References}

AII. (2010). Regional stakeholder workshop on infectious disease surveillance in Eastern Africa, Imperial Royale Hotel, 3-4 March 2010, Kampala. Workshop report. Kampala, Uganda: Africa Innovations Institute.

Backman, G., Hunt, P., Khosla, R., Jaramillo-Strouss, C., Fikre, B. M., Rumble, C., Pevalin, D., Acurio Páez, D., Armijos Pineda, M., Frisancho, A., Tarco, D., Motlagh, M., Farcasanu, D., \& Vladescu, C. (2008). Health systems and the right to health: an assessment of 194 countries. Lancet, 372(9655), 2047-2085.

Balabanova, D., McKee, M., Mills, A., Walt, G., \& Haines, A. (2010). What can global health institutions do to help strengthen health systems in low income countries? Health Research Policy and Systems, 8, 22.

Bashaasha, B., Mangheni, M. N., \& Nkonya, E. (2011). Decentralization and rural service delivery in Uganda. Washington DC: International Food Policy Research Institute. IFPRI Discussion Paper 01063.

Bentley, J. W., Boa, E., Danielsen, S., Franco, P., Antezana, O., Villarroel, B., Rodriguez, H., Ferrufino, J., Franco, J., Pereira, R., Herbas, J., Díaz, O., Lino, V., Villarroel, J., Almendras, F., \& Colque, S. (2009). Plant health clinics in Bolivia 2000-2009: operations and preliminary results. Food Security, 1(3), 371-386.

Boa, E. (2009). How the global plant clinic began. Outlooks on Pest Management, 20(3), 112-116. 
Bowser, D., Sparkes, S.P., Mitchell, A., Bossert, T.J., Bärnighausen, T., Gedik, G., \& Atun. R. (2013). Global fund investment in human resources for health: innovation and missed opportunities for health system strengthening. Health Policy and Planning, (published online: November 6, 2013.

Braa, J., Heywood, A., \& Sahay, S. (2012). Improving quality and use of data through data-use workshops: Zanzibar, United Republic of Tanzania. Bulletin of the World Health Organization, 90(5), 379-384.

Browning, J. A. (1983). Whither plant pathology? Whither plant health? Plant Disease, 67(5), 575.

Catley, A., Leyland, T., Mariner, J. C., \& Akabwai, D. M. O. (2004). Para-veterinary professionals and the development of quality, selfsustaining community-based services. Revue Scientifique et Technique, 23(1), 225-252.

Danielsen, S., \& Kelly, P. (2010). A novel approach to quality assessment of plant health clinics. International Journal of Agricultural Sustainability, 8(4), 257-269.

Danielsen, S. \& Mutebi, E. (2010). The introduction of mobile plant clinics to Uganda: First results and lessons learned 2005-2010. Working paper 1. Centre for Health Research and Development (DBL), Faculty of Life Sciences, University of Copenhagen, Denmark.

Danielsen, S., Centeno, J., Lopez, J., Lezama, L., Varela, G., Castillo, P., Narvaez, C., Zeledon, I., Pavon, F., \& Boa, E. (2013a). Innovation in plant health services in Nicaragua: from grassroots experiment to a systems approach. Journal of International Development, 25(7), 968-986.

Danielsen, S., Boa, E., Mafabi, M., Mutebi, E., Reeder, R., Kabeere, F., \& Karyeija, R. (2013b). Using plant clinic registers to assess the quality of diagnoses and advice given to farmers: a case study from Uganda. The Journal of Agricultural Education and Extension, 19(2), 183-201.

Danielsen, S., Matsiko, F. B., \& Kjær, A. M. (2014). Implementing plant clinics in the maelstrom of policy reform in Uganda. Food Security, 6(6), 807-818.

Dash, U., Muraleedharan, V. R., Prasad, B. M., Acharya, D., Dash, S., \& Lakshminarasimhan, S. (2008). Access to health services in under privileged areas a case study of mobile health units in Tamil Nadu and Orissa. Consortium for Research on Equitable Health Systems: London, UK.

Hanson, K., Ranson, M. K., Oliveira-Cruz, V., \& Mills, A. (2003). Expanding access to priority health interventions: a framework for understanding the constraints to scaling-up. Journal of International Development, 15(1), 1-14.

Kruk, M. E., \& Freedman, L. P. (2008). Assessing health system performance in developing countries: a review of the literature. Health Policy, 85(3), 263-276.

Kruk, M. E., Porignon, D., Rockers, P. C., \& Van Lerberghe, W. (2010). The contribution of primary care to health and health systems in low- and middle-income countries: a critical review of major primary care initiatives. Social Science \& Medicine, 70(6), 904-911.

MAAIF. (2010). Development strategy and investment plan 2010/112015/16. Entebbe, Uganda: Ministry of Agriculture Animal Industry and Fisheries.

MAAIF. (2011a). Plant health clinics in Uganda - exchange, learn and plan for next generation plant health clinics in Uganda. Workshop report. Entebbe, Uganda: Ministry of Agriculture Animal Industry and Fisheries

MAAIF. (2011b). Ministerial policy statement, 30 July 2011. Entebbe, Uganda: Ministry of Agriculture Animal Industry and Fisheries.

Miller, S., Beed, F. D., \& Harmon, C. L. (2009). Plant disease diagnostic capabilities and networks. Annual Review of Phytopathology, 47, $15-38$.

Mills, P., Dehnen-Schmutz, K., Ilbery, B., Jeger, M., Jones, G., Little, R., MacLeod, A., Parker, S., Pautasso, M., Pietravalle, S., \& Maye, D. (2011). Integrating natural and social science perspectives on plant disease risk, management and policy formulation. Philosophical
Transactions of the Royal Society of London. Series B, Biological Sciences, 366(1573), 2035-2044.

Mitchell, A., \& Bossert, T. J. (2010). Decentralisation, governance and health-system performance: "where you stand depends on where you sit". Development Policy Review, 28(6), 669-691.

Murray, C. J. L., \& Frenk, J. (2000). A framework for assessing the performance of health systems. Bulletin of the World Health Organization, 78(6), 717-731.

Negussie, E., Karanja, P., Day, R., Romney, D., Reeder, R., Boa, E., Muriithi, C., Kamau, R., Phiri, N., Danielsen, S., Murage, N., Gitare, I., Wanjiku, R., Mutisya, J., Ngige, D., Kimani, M. \& Festus, W. 2011. The role of plant health clinics towards meeting the needs of smallholder farmers for advisory services: Experiences from East Africa. Proceedings of Innovations in Extension and Advisory Services International Conference. Nairobi: Technical Centre for Agricultural and Rural Cooperation (CTA).

Oliveira-Cruz, V., Hanson, K., \& Mills, A. (2003). Approaches to overcoming constraints to effective health service delivery: a review of the evidence. Journal of International Development, 15(1), 41-65.

Pallas, S. W., Curry, L., Bashyal, C., Berman, P., \& Bradley, E. H. (2012). Improving health service delivery organisational performance in health systems: a taxonomy of strategy areas and conceptual framework for strategy selection. International Health, 4(1), 20-29.

Romney, D., Day, R., Faheem, M., Finegold, C., LaMontagneGodwin, J., \& Negussie, E. (2013). Plantwise : putting innovation systems principles into practice. Agriculture for Development, 18, 27-31.

Rwamigisa, P., Birner, R., Mangheni, M. \& Semana, A. (2013). How to promote reforms in the agricultural sector? A case study of Uganda's National Agricultural Advisory Services (NAADS). Paper presented at the International Conference on the "Political Economy of Agricultural Policy in Africa". 18-20 March, Pretoria.

Sandall, J., Cooksey, R., \& Wright, V. (2011). A systems approach to identifying and managing opportunities and constraints to delivering innovation policy for agriculture : an analysis of the Australian Cooperative Research Centres (CRC) program. The Journal of Agricultural Education, 17(5), 37-41.

Shakarishvili, G., Atun, R., Berman, P., Hsiao, W., Burgess, C. \& Lansang M.A. (2010). Converging health systems frameworks: towards a concepts-to-actions roadmap for health systems strengthening in low- and middle-income countries. Global Health Governance, $I V(1)$.

Shengelia, B., Tandon, A., Adams, O. B., \& Murray, C. J. L. (2005), Access, utilization, quality, and effective coverage: an integrated conceptual framework and measurement strategy. Social Science \& Medicine, 61(1), 97-109.

Smith, J. J., Waage, J., Woodhall, J. W., Bishop, S. J., \& Spence, N. J. (2008). The challenge of providing plant pest diagnostic services for Africa. European Journal of Plant Pathology, 121(3), 365-375.

Sseguya, H., Mazur, R., Abbott, E., \& Matsiko, F. (2012). Information and Communication for rural innovation and development: context, quality and priorities in southeast Uganda. The Journal of Agricultural Education and Extension, 18(1), 55-70.

Vega, J. (2013). Universal health coverage: the post-2015 development agenda. Lancet, 381, 179-180.

Wendt, C., Frisina, L., \& Rothgang, H. (2009). Healthcare system types: a conceptual framework for comparison. Social Policy and Administration, 43(1), 70-90.

WHO. (2007). Everybody's business: strengthening health systems to improve health outcomes: WHO's framework for action. Geneva: World Health Organization.

WHO. (2008). Report on the review of primary healthcare in the African region. World Health Organization, Regional Office for Africa. 


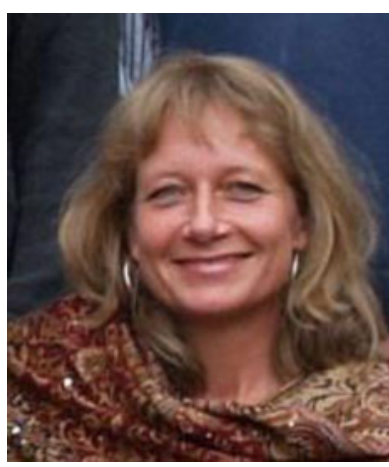

Solveig Danielsen is Research Coordinator of Plantwise, CABI. She holds a $\mathrm{PhD}$ in plant pathology from University of Copenhagen. She has 20 years of experience working in different aspects of plant health, agricultural research and extension, policies and institutions in developing countries. She has lived and worked in Costa Rica (CATIE), Peru (CIP), Nicaragua (FUNICA) and Uganda (Makerere University). Before joining CABI in 2012 she was an associate professor at Centre for Health Research and Development, University of Copenhagen, where she and co-workers developed new concepts and approaches to plant health systems research.

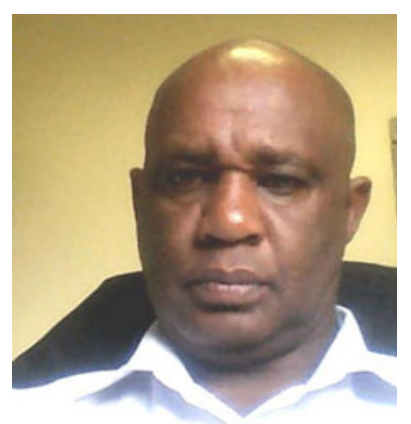

Frank B. Matsiko is Lecturer at the Department of Agricultural Extension and Innovation, Makerere University, Uganda. He holds a PhD in Agricultural Extension from Makerere University. He has 9 years of experience working in administrative and grassroots agricultural extension. For a period extending over 25 years he has taught and researched agricultural and rural development policies and institutions in Uganda. 